\title{
O consumo de alimentos no circuito inferior da economia urbana e a segurança alimentar na Vila Ouro Verde em Ponta \\ Grossa, PR
}

\author{
El consumo de alimentos en el circuito inferior de la economía \\ urbana y la seguridad alimentaria en Vila Ouro Verde en Ponta \\ Grossa, PR
}

\section{The Consumption of Food in the Lower Circuit of the Urban Economy and Food Security in the Vila Ouro Verde in Ponta Grossa, PR}

\author{
Rogério Gomes dos Santos \\ rogeriogsantos2707@gmail.com \\ Escolas SESI Avaré "Israel Dias Novaes"
}

Luiz Alexandre Gonçalves Cunha cunhageo@uepg.br

PPPG em Geografia - Universidade Estadual de Ponta Grossa

Resumo. O objetivo do texto é analisar a relação entre o consumo de alimentos no circuito inferior da economia urbana e a segurança alimentar. $\mathrm{O}$ debate proposto demonstra que a localização contribui na definição da posição de consumo, cabendo aos moradores pobres da periferia urbana um macroambiente alimentar em que se predominem os empreendimentos do circuito inferior. O recorte espacial da análise é a comunidade da Vila Ouro Verde situada no bairro Maria Otília, em Ponta Grossa-PR. Constatou-se que os preços mais elevados praticados nos comércios locais aliados à baixa qualidade dos produtos podem provocar a ocorrência da insegurança alimentar.

Palavras Chave: Circuitos da economia urbana. Fome. Ponta Grossa

Resumem. El objetivo del trabajo es analisar la relación entre el consumo de alimentos en el circuito inferior de la economía urbana y la seguridad alimentar. El debate propuesto muestra que la ubicación ayuda en la definición de la posición del consumo, dejando los residentes pobres de la perifería urbana en un macro ambiente alimentar donde predominan los comercios del circuito inferior. El área espacial del análisis es la Villa Ouro Verde, que está ubicada en el barrio Colonia Dona Luiza, en Ponta Grossa-PR. Se encontró que los mayores precios practicados en los comercios locales aliados a la baja calidad de los productos pueden causar la aparición de la inseguridad alimentaria.

Palabras clave: Circuitos de la economía urbana. Hambre. Ponta Grossa.

Abstract. The objective of the text is to analyze the relationship between food consumption in the lower circuit of the urban economy and food security. The proposed 
debate demonstrates that localization contributes to the definition of the consumption position, and poor residents of the urban periphery have a food macro-environment in which the lower circuit enterprises predominate. The spatial analysis is the Vila Ouro Verde community located in the Maria Otília neighborhood, in Ponta Grossa-PR. It has been found that higher prices in local trades coupled with poor product quality may lead to food insecurity.

Keywords: Circuits of the urban economy. Famine. Ponta Grossa

\section{INTRODUÇÃO}

Este artigo se propõe analisar a relação entre a proximidade da população da periferia urbana para com o consumo de alimentos em empreendimentos do circuito inferior e a relação deste tipo de consumo para com a segurança alimentar. $\mathrm{O}$ debate proposto demonstra que estes empreendimentos encontram-se mais presentes na periferia urbana e que o consumo nestes estabelecimentos pode acirrar para o morador pobre da periferia urbana a ocorrência da fome quantitativa e qualitativa.

A análise do acesso à alimentação em quantidade e qualidade relacionada à dinâmica da economia urbana, proposta nesta pesquisa, tem como grande inspiração as obras de Josué de Castro, pioneiro no estudo multidisciplinar da fome. O autor apresenta a Geografia como a disciplina por excelência para abordar esta multidisciplinaridade e demonstra o quanto a espacialidade tem implicação sobre o fenômeno da fome.

Apesar da extrema importância da obra de Castro (1946), suas análises se deram principalmente sobre o cenário de um Brasil predominantemente rural. Hoje, segundo o censo demográfico do IBGE (2010), 84\% da população brasileira vivem em áreas urbanas, de modo que se deve considerar que as influências das dinâmicas espaciais para aquisição de alimentos, bem como as táticas de sobrevivência, são diferentes nestes dois cenários.

Para compreender essa dinâmica foram entrevistadas 74 famílias residentes no loteamento Ouro Verde em Ponta Grossa-PR. A pesquisa está baseada na vivência obtida durante a realização de estágio na Prefeitura Municipal de Ponta Grossa (PMPG) no ano de 2012, que tinha por objetivo sua regularização fundiária. A vivência na comunidade, bem como o acesso a literatura específica, fez perceber que a dinâmica econômica local possui muitas das características apresentadas por Santos (1979) como aquelas referentes ao circuito inferior.

A Vila Ouro Verde surgiu de uma ocupação que ocorreu no ano de 2001 e desde então as famílias esperam do Estado a regularização e promoção de uma vida digna. Em 14 anos esperava-se que a comunidade pudesse usufruir de melhores padrões de moradia com um mínimo necessário para sua subsistência, o que impactaria, inclusive, no direito ao acesso a uma boa alimentação. Desse modo, o interesse em estudar a comunidade Ouro Verde motiva-se pela realidade do núcleo ser a personificação das mazelas sociais encontradas na organização espacial urbana. 
A análise também se fundamenta na sistematização realizada por Duran (2013) sobre o microambiente e macroambiente alimentar. O primeiro refere-se ao espaço interno dos empreendimentos de venda de alimentos e o segundo refere-se à densidade, localização e proximidade dos empreendimentos a residência.

Para a análise do macroambiente alimentar efetuou-se um mapeamento demonstrando a espacialização por bairros dos empreendimentos de venda de alimentos para consumo na residência considerados do circuito superior e inferior na cidade de Ponta Grossa. Como empreendimentos pertencentes ao circuito superior consideraram-se os hipermercados e supermercados e, como pertencentes ao circuito inferior, os minimercados e mercearias. Para tal, utilizou-se de dados adquiridos através da Junta Comercial e Empresarial do Paraná (JUCEPAR), que recolhe informações cadastrais no momento do registro de abertura da empresa.

Para efetivação da análise do microambiente alimentar, levaram-se em consideração as características das mercearias da Vila Ouro Verde e o preço dos alimentos praticados nas mesmas. Para análise sobre os preços praticados realizou-se um comparativo do valor da cesta básica de alimentos calculada nestes empreendimentos em relação aos praticados nos hipermercados da cidade de Ponta Grossa, calculado e divulgado pelo Centro de Estudos e Pesquisas Rouger Miguel Vargas (CEPRMV), vinculado à Universidade Estadual de Ponta Grossa (UEPG).

A pesquisa, visando permitir a comparação pretendida, buscou participação dos levantamentos dos valores das cestas junto com a equipe de pesquisadores do Centro para compreender o trabalho de campo, com o objetivo de entender a metodologia de coleta para poder aplicá-la nos levantamentos a serem realizados pelo próprio pesquisador. $\mathrm{O}$ comparativo refere-se ao dia 26 de Maio de 2014, quando a equipe do Centro pesquisou em seis estabelecimentos de grande porte, e o pesquisador, nas mercearias da Vila Ouro Verde. Considerou-se como fator preponderante para efeitos qualitativos e quantitativos na compra de alimentos, o consumo nos supermercados modernos e em relação às pequenas mercearias locais. A menor diversidade de produtos aliado ao valor mais oneroso dos pequenos comércios locais apresentaram-se como possíveis agravantes da fome qualitativa e quantitativa.

Foram investigados os fatores que levam a aproximação da população da Vila Ouro Verde para com o consumo nas pequenas mercearias locais. Evidenciou-se que aspectos econômicos, de mobilidade e culturais foram determinantes na 'escolha' ${ }^{1}$ da realização das compras nos comércios da Vila.

O estudo divide-se em três partes, a primeira corresponde à revisão de literatura e versa sobre a teoria dos circuitos da economia urbana proposta por Santos (1979). Na segunda parte do texto, realiza-se a análise do macroambiente alimentar, efetuou-se um mapeamento demonstrando a espacialização por bairros dos empreendimentos de venda de alimentos para consumo na residência considerados do circuito superior e inferior

1 Para alguns entrevistados não existia a possibilidade da escolha, devido à falta de recursos econômicos e dificuldades de mobilidade. 
na cidade de Ponta Grossa. Na terceira seção são apresentados os resultados atingidos, onde se apurou que os preços mais onerosos dos alimentos praticados nos pequenos comércios da Vila, aliados à preferência destes por produtos mais baratos e via de regra de menor qualidade nutritiva, pode favorecer a ocorrência da fome quantitativa e qualitativa. Percebe-se que as segregações espaciais aliadas às características socioeconômicas em que os moradores estão engendrados influenciam na hora de adquirir alimentos nos mercadinhos da vila.

\section{OS CIRCUITOS DA ECONOMIA URBANA E O ACESSO A ALIMENTAÇÃO}

A seletividade do espaço geográfico no nível econômico e social origina o que Santos (1979) denomina como circuitos superior e inferior da economia urbana nos países subdesenvolvidos. As desigualdades de renda entre os citadinos, cria na sociedade urbana um conjunto de diferenças qualitativas e quantitativas de consumo. Estas diferenças são a fonte da manutenção dos dois circuitos de produção, distribuição e consumo de bens e serviços, onde as diferenças fundamentam-se, conforme Santos (1979, p.29): “O circuito que se beneficia da modernização tecnológica, e o outro que é resultado da mesma modernização, mas de forma indireta e que se beneficia parcialmente ou não se beneficia dos progressos técnicos".

O circuito superior desempenha atividades consideradas modernas, ligadas ao capital hegemônico, as populações ligadas a este circuito pertencem em síntese às classes médias e altas. Já as atividades do circuito inferior são aquelas consideradas 'não modernas', da qual as populações ligadas a ela tanto na produção quanto no consumo são do substrato social pobre. As atividades urbanas e as populações a elas ligadas variam conforme o grau de tecnologia, organização e capital. Quando os níveis são altos, pertencem ao circuito superior, quando são baixos, ao circuito inferior (SANTOS, 1979).

Em síntese, o circuito superior é constituído "[...] pelos bancos, comércio e indústria de exportação, indústria urbana moderna, serviços modernos, atacadistas e transportadores". Ao contrário, o circuito inferior, conforme Santos (1979, p.31), “[...] é constituído essencialmente por formas de fabricação não capital intensivo, pelos serviços não modernos fornecidos a varejo e pelo comércio não moderno e de pequena dimensão".

Segundo Sposito (2000), nas cidades dos anos de 1960 e 1970, época da conceituação dos circuitos realizada por Santos (1979), era mais nítido identificar as diferenças entre os dois circuitos. Para o autor, atualmente encontram-se dificuldades em sua identificação de maneira clara e objetiva, pois aumentaram a interpenetração das atividades entre ambos os circuitos. Um exemplo que pode ser citado é o uso de cartões de crédito nos pequenos comércios do circuito inferior, uma forma moderna de compra em empreendimentos 'não modernos'.

Apesar de apontar para a necessidade de atualização da teoria dos circuitos de Santos (1979), Sposito (2000) afirma que a mesma continua atualizada ao se tratar da economia urbana dos países subdesenvolvidos. Para o autor, a teoria de Santos (1979) 
ainda não foi esgotada, muito menos superada e que, no atual momento ainda não teria sido estabelecida graças a pouca participação dos geógrafos brasileiros em aplicá-la. Em tese, "a teoria foi mais esquecida que debatida, foi mais abandonada do que superada" (SPOSITO, 2000, p.50).

Apesar de se considerar que ambos os circuitos são frutos de suas inter-relações em diferentes escalas, a pesquisa desdobra-se com mais afinco sobre o circuito inferior, por considerar que o cenário formado por esse apresenta relações mais diretas com a questão da fome urbana. Não se evidencia que a economia da periferia urbana represente o circuito inferior, pois este é um fenômeno muito mais amplo e não delimitado geograficamente. Todavia, muitas de suas características apresentam-se nas economias das periferias urbanas.

O circuito inferior é fruto da concentração da ação conjugada do Estado, que concentra a riqueza da nação no fornecimento de infraestruturas para o setor moderno, e do circuito superior, beneficiário da ação do Estado e concentrador de renda. $\mathrm{O}$ circuito inferior é resultado da ação indireta do processo modernizador, fruto das ações desempenhadas pelos agentes hegemônicos, responsáveis por uma distribuição de renda cada vez mais injusta e espacialmente concentrada, que força uma diminuição da capacidade de consumo das massas. A demasiada concentração de capital nos setores modernos do circuito superior impede os investimentos no circuito inferior, fazendo com que a queda das rendas das pessoas ocupadas neste último aumente (SANTOS, 1979).

Sem muitas possibilidades de participar de uma economia moderna, a população de baixa renda consegue produzir e consumir por intermédio da economia do circuito inferior, a qual não se pode chamar de tradicional porque também é fruto do mesmo processo modernizador. Pois, "toda a economia e sociedade estão penetradas por elementos de modernização, se bem que em diferentes níveis quantitativos e qualitativos" (SANTOS, 1979 , p.15). Assim, a economia do circuito inferior está intimamente relacionada com o local, enquanto a economia moderna está frequentemente preocupada com o global. Suas diferenças em repercussões espaciais se evidenciam a partir da capacidade de macro-organização espacial do circuito superior, que não ocorre no circuito inferior (SANTOS, 1979).

A economia do circuito inferior é composta por atividades de pequena dimensão, criada como forma de sobrevivência para grande parte da população. Ela corresponde à pequena produção manufatureira, comumente artesanal, assim como ao pequeno comércio e a uma variedade de serviços de toda espécie. Por não demandar, na maioria das vezes, de qualificação profissional, a entrada no mercado de trabalho do circuito inferior é via de regra mais facilitada (SANTOS, 1979).

O circuito inferior constitui ainda uma forma de abrigo, de sobrevivência, dos citadinos carentes de capital e qualificação profissional. Esta forma de sobrevivência encontra seus recursos no próprio local. Este aspecto também é abordado por Santos (1979, p.154) ao defender que "pobreza e circuito inferior aparecem com relações de causa e efeito inegáveis".

Enquanto no circuito superior a concentração de capital é o essencial, no circuito inferior é a força-trabalho que assegura a sobrevivência das famílias de baixa renda. $\mathrm{O}$ 
emprego no circuito inferior se define pelo trabalho mal remunerado e o trabalho instável ou temporário.

O processo de industrialização ocorrido nos países emergentes, apesar de atrair um grande coeficiente de capital e um considerável contingente de pessoas ocupadas, não é capaz de fornecer empregos suficientes. Diferente do que ocorreu nos países desenvolvidos durante seu processo de industrialização, nos países em desenvolvimento formou-se um grande contingente de mão de obra não utilizada pela transformação modernizadora. Estas circunstâncias fizeram com que desde o início de sua modernização, as cidades formassem um setor terciário mais importante do que o secundário (SANTOS, 1979).

A terceirização tornou-se a fonte de emprego para essa população empobrecida que raramente pode consumir ou trabalhar no circuito moderno. Estes construíram um terciário de outra natureza, ou como prefere Santos (1979), um terciário 'refúgio'. Este traz como característica o principal subsistema do circuito inferior, o comércio. O comércio no circuito inferior é caracterizado por sua íntima relação com o local, e possui um número muito grande de empreendimentos de pequena dimensão.

Vennetier (1969) citado por Santos (1979), afirma ter se espantado com a densidade da pulverização de comércios nos países subdesenvolvidos, levando a dizer que "tem tantos comércios que dá a impressão as vezes que todo mundo tem alguma coisa para vender" (1979, p.168). Esta pulverização é resultado do contexto socioeconômico e geográfico, uma característica própria do circuito inferior, que têm na pobreza e na segregação socioespacial sua força motriz.

Contudo, uma tal pulverização das atividades de comércio tem explicações geográficas e sócio-economicas. De um lado, os habitantes dos bairros pobres compram no local; o preço dos transportes não lhes permite ter acesso ao comércio moderno, frequentemente situado nos centros das cidades ou nos seus arredores. A densidade e distribuição das lojas estão calcadas nas possibilidades de deslocamento a pé da clientela. De outro lado, a dimensão dos comércios é uma adaptação a um consumo pequeno e irregular. A venda a micro varejo permite ao cliente pobre, que só dispõe de magras rendas no dia-a-dia, abastecer-se em pequenas quantidades. Mas, é sobretudo o crédito, mais difundidos em certas zonas residenciais que no centro, que permite a vida do pequeno comércio (SANTOS, 1979, p. 168).

A pulverização de comércios atende a uma lógica de consumo, em que pesa principalmente o acesso a pé dos clientes, normalmente pessoas em seus espaços de vizinhança. Esses comércios são adaptados à realidade local, onde a renda é baixa e instável, a qual não comporta a realização de grandes compras. Esta população de renda oscilante e baixa tem por característica comprar pouco, mas comprar todos os dias (SANTOS, 1979).

Estes estabelecimentos comerciais geralmente apresentam pouco espaço físico, muitas vezes ocorrem nas próprias residências, o que constitui para os comerciantes uma economia de dinheiro e tempo. Esses comércios estão prontos a atender o fracionamento na compra por parte dos clientes, abastecendo-se em pequenas quantidades todos os dias, para garantir uma diversidade de estoque num pequeno espaço físico. Desta maneira, o 
comerciante só estoca o que pode vender rapidamente, visto que na maioria das vezes não estão preparados para conservar os gêneros perecíveis.

A pulverização dos comércios também dissolve suas possibilidades de acumulação de capital. O dinheiro no circuito inferior circula rápido entre os inúmeros intermediários, impedindo sua concentração. Seu objetivo é garantir a sobrevivência da família e não a acumulação. Não sendo os ganhos elevados, muitas vezes os comerciantes acabam trabalhando por longas horas com o objetivo de garantir o sustento da família (SANTOS, 1979).

É característica do circuito inferior a grande margem de lucro por produto e uma baixa margem de lucro global. Por venderem pouco e muitas vezes a crédito, os comerciantes tem que elevar o lucro por unidade, entretanto o lucro global continua relativamente pequeno (SANTOS, 1979). Estas circunstâncias asseveram para os consumidores do circuito inferior a intensa exploração do consumo.

O grande número de intermediários e o fracionamento da mercadoria contribuem também para esse acréscimo dos preços, segundo Santos (1979, p. 191) “o fracionamento da mercadoria provoca uma majoração espantosa dos preços a varejo para o consumidor da extremidade da cadeia, ou seja, o cliente pobre". Em contrapartida, a compra de produtos em grandes quantidades possibilita menores gastos, o que tem levado muitas pessoas à compras nos atacados.

A autossubsistência é dificultada nas cidades na medida em que se aumenta a urbanização. Nos espaços urbanos o acesso à alimentação se dá majoritariamente a partir do dinheiro. Segundo Casemiro, Valla e Guimarães (2010, p. 2087) “(...) no contexto urbano, são as relações mercantis que predominam quando se trata de aquisição de alimentos". Enquanto nas áreas rurais os rendimentos não monetários ${ }^{2}$ são a segunda principal fonte de renda correspondendo a 20,8\% da mesma, nas áreas urbanas corresponde a 14,7\% (IBGE, 2010). Nem sempre tendo o dinheiro em espécie (IBGE, 2010), 85\% das famílias brasileiras sentem alguma dificuldade para chegar ao final do mês com seus rendimentos. As famílias mais pobres, mesmo aqueles com renda fixa, tem de recorrer frequentemente à usura, ao popular 'fiado', para sua segurança alimentar. Este cenário tem como resultado um endividamento generalizado da população, entretanto, o mesmo varia muito conforme a classe social. Enquanto as classes mais abastadas se endividam com maior frequência com despesas ocasionais, os pobres se endividam com despesas correntes, como a alimentação. De modo geral, o comprometimento da renda para com a alimentação tende a diminuir com o aumento das rendas (IBGE, 2010).

O 'fiado', por sua vez, demanda capital social, expresso nas regras de reciprocidade, a qual Putnam (2006), argumenta ser sustentada pela reputação, honestidade e confiabilidade de seus participantes. Tanto o cliente quanto o comerciante têm que honrar com as regras de reciprocidade para que ocorra a confiança mútua da prática do 'fiado'. Pelo fato da compra depender de um contrato social de cunho moral, e não legal, o comerciante depende que o cliente honre com sua dívida; da parte do cliente, ele depende que o

2 Segundo o IBGE rendimentos não monetário são: “aquelas efetuadas sem pagamento monetário, ou seja, aquisição obtida através de doação, retirada do negócio, troca, produção própria, pescado, caçado e coletado[...] (IBGE, 2010, p.21). 
comerciante não trapaceie e superfature sua conta. A sanção para quem transgredir esse contrato social/moral não é penalizada perante os ditames da lei, mas a partir da exclusão da rede de solidariedade e cooperação (PUTNAM, 2006). Para aqueles que não honrarem com as dívidas existe uma enorme perda de capital social que afeta para além da relação com o credor em questão, pois neste desenrolar " [...] a cadeia de relações sociais permite transmitir e disseminar confiança: confio em você porque confio nela, e ela me garante que confie em você" (PUTNAM, 2006, p.179). Entende-se que a confiança e consequentemente a desconfiança, é algo que se empresta, podendo sua disseminação ser muito grande e os malefícios derivados de sua falta se alastrar a uma miríade de relações socioeconômicas e socioculturais do indivíduo.

Em comunidades pequenas e coesas este tipo de confiança é mais facilmente alcançável, entretanto, em contextos mais amplos e complexos é preciso haver uma forma de confiança mais impessoal ou indireta (PUTNAM, 2006). Na Vila pesquisada existe um grande número de pequenos estabelecimentos comerciais, que mantém seu comércio muito vinculado com o local e atuam de forma pessoal com seus clientes. Isto é demonstrado quando $53 \%$ das pessoas pesquisadas afirmam fazer uso da prática do 'fiado'. Todos realizam o mesmo em pequenos estabelecimentos, evidencia-se que tal prática está vinculada às características socioespaciais, socioeconômicas e culturais próprias de espaços periféricos.

$\mathrm{O}$ 'fiado' constitui uma alternativa de crédito para aquelas pessoas que se encontram muitas vezes impossibilitadas a participar do engessado sistema do crédito formal. Entretanto, mesmo sendo o 'fiado' uma modalidade de crédito mais flexível, o mesmo não está assegurado a todos, mas sim àqueles que podem honrar com as dívidas e possuírem um bom estoque de capital social que preservem intacto o quesito confiança. Portanto, o fracionamento da mercadoria, o capital social expresso no crédito fiado e a inviabilidade de consumir no mercado moderno traçam a subjetividade do consumo no circuito inferior, entre eles o consumo vinculado à alimentação. A lógica dessa questão se encerra principalmente a uma análise material e não cultural.

Assim, não está em condições de se dirigir ao comércio moderno, em geral implantado longe dos bairros pobres e cujo crédito é reservado às pessoas que podem pagar. Por outro lado, os produtos vendidos no comércio moderno, como os supermercados, por exemplo, são padronizados e indivisíveis e as relações entre os agentes e os clientes são impessoais. Somente o pequeno comércio do circuito inferior está adaptado às condições da clientela pela venda a crédito e pelo fracionamento das mercadorias (LASSERE, 1958, pp. 184-185 apud SANTOS, 1979, p. 189).

Num contexto no qual domina esse padrão, é possível afirmar:

Como Vennetier (1960) observou o comércio varejista 'responde a uma necessidade econômica; o comprador pode ter 10 francos por dia para obter oito torrões de açúcar, mas não tem 80 francos para comprar um quilo de uma vez'. Não é que a população pobre seja indiferente a noção de preço, como pensam alguns. Seria um erro interpretar esse comportamento pelos dados culturais. Na realidade, trata-se do único tipo de 
relação econômica possível nas condições de funcionamento da economia urbana pobre (SANTOS, 1979, p. 189).

O circuito inferior tem historicamente desempenhado um importante papel social ao abrigar as populações desvalidas do processo modernizador, como os migrantes e imigrantes, as populações do campo, entre outros. Contudo, ele acaba agindo como perpetuador da pobreza, coletando os rendimentos populares através de uma vasta gama de intermediários, para concentrar-se posteriormente no circuito superior (SANTOS, 2009).

Para Santos (1979), a solução dos problemas evidenciados nesse cenário só seria possível através da substituição do atual sistema de relações entre os circuitos por outro sistema. Uma relação em que não impere os objetivos econômicos exportados e importados, que não privilegie tendências à concentração econômica e espacial, mas sim um sistema que valorize a economia local e o desenvolvimento socioespacial equitativo em todo o país. As barreiras a serem quebradas parecem ser grandes:

Enquanto a produtividade econômica não ceder lugar a produtividade social, onde o crescimento não teria sentido se não fosse a serviço de todos, a procura do lucro substituída as preocupações com a equidade, o Estado ao invés de favorecer o setor moderno, tirar-se partido deste para fortalecer o não moderno, tirando partido da modernização em prol da maioria da população, realizando um aumento da produtividade per capta no circuito inferior e no campo, assim diminuindo o fosso entre o circuito moderno e o circuito inferior, onde este teria sua natureza e significado mudados. Acarretando por uma melhor distribuição da produção e organização do espaço, aumentando o poder de participação das cidades intermediárias e locais (SANTOS, 1979, p. 291).

A análise do consumo no circuito inferior leva a entender que o consumidor pobre é injustamente punido, pois tem que comprar na extremidade da cadeia de intermediários. Por não possuir uma renda satisfatória e residir muitas vezes em espaços segregados entre outros determinantes, tem que desembolsar relativamente mais por sua subsistência.

Para Peet (1982), cada grupo social teria um 'prisma' diário de diferentes tamanhos onde se movimenta, e no qual, principalmente para as classes sociais mais pobres, se converteria numa prisão, sob o ponto de vista de espaços e recursos. A 'prisão' socioespacial nos termos de Peet (1982), contextualizada no consumo do circuito inferior, parece punir os citadinos pobres também pelo custo de vida. Tanto trabalhar quanto consumir no circuito inferior apresenta-se como agravante da pobreza, e inclui-se aqui, o agravante da fome.

Não há dúvida que a fome está condicionada ao acesso a alimentação. Nessa esteira, percebe-se a instauração de um ciclo de pobreza em que o cidadão cumpre uma fatigante jornada de trabalho, muitas vezes no mercado informal que permeia este circuito inferior, e mesmo com baixa remuneração se vê obrigado a fazer frente aos preços mais altos que transitam neste mercado. 


\section{A DISTRIBUIÇÃO DOS SUPERMERCADOS, HIPERMERCADOS, MINIMERCADOS E MERCEARIAS NA CIDADE DE PONTA GROSSA}

A partir do entendimento da dinâmica de funcionamento dos circuitos da economia urbana, percebe-se que existe uma grande importância do circuito inferior no comércio varejista urbano. Acrescenta-se ao aporte teórico a vivência do autor no município de Ponta Grossa, na qual se evidenciou grande quantidade de pequenas mercearias em bairros pobres, principalmente quando da realização de estágio na prefeitura do município, na qual se pode ter contato com todas as vilas e bairros da cidade.

Verificaram-se os empreendimentos de venda de alimentos para consumo na residência, especificados no conselho nacional de atividades econômicas como supermercados, hipermercados ${ }^{3}$, minimercados e mercearias ${ }^{4}$, elencados pelo Código Nacional de Atividades Econômica (CNAE) como 4711301, 4711302 e 4712100, respectivamente. Consideram-se como empreendimentos de localidade máxima os hipermercados e supermercados, e de localidade mínima os minimercados e mercearias.

Analisando o valor do capital social ${ }^{5}$ investido em ambos a partir dos dados fornecidos pela Junta Comercial e Empresarial do Paraná (JUCEPAR). Nos dois tipos de empreendimentos, tem-se que os super e hipermercados totalizam 99 empreendimentos no município.

Tem-se que o montante do capital social dos empreendimentos de alcance máximo é duas vezes e meia maior dos de localidade mínima, com uma média de capital social 2,6 vezes também superior. Entretanto, o número de empreendimentos de alcance mínimo é mais de dez vezes superior o de alcance máximo. Estas relações estão expressas no gráfico que segue.

Figura 01- Valor do capital social e número de empreendimentos de localidade máxima e mínima

\section{Valor do capital social Número de empreendimentos}

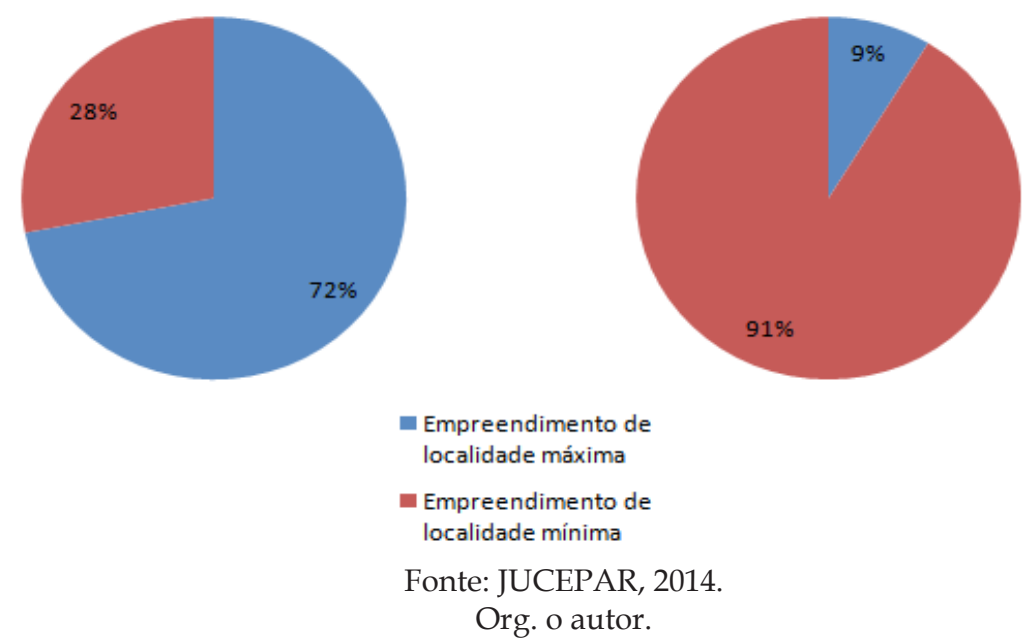

3 Segundo a descrição das atividades econômicas do CNAE: Super e hipermercados compreendem: atividades dos estabelecimentos comerciais com venda predominante de produtos alimentícios variados e que também oferecem um gama variada de outras mercadorias, tais como: utensílios domésticos, produtos de limpeza e higiene pessoal, roupas, ferragens, etc. com área de venda Supermercados: de 300 a 5.000 m2; hipermercados superior a $5.000 \mathrm{~m} 2$.

4 Minimercados, mercearias e armazéns compreendem segundo a descrição das atividades econômicas do CNAE: as atividades dos estabelecimentos comerciais com e sem autoatendimento e com venda predominante de produtos alimentícios variados em minimercados, mercearias, armazéns, empórios, secos e molhados, com área de venda inferior a $300 \mathrm{~m} 2$.

5 Capital social refere-se ao montante necessário para se constituir e iniciar as atividades de uma nova empresa enquanto esta não gera recursos próprios para se sustentar. 
Estes dados apresentam de maneira aproximada as disparidades no valor dos empreendimentos, aproximada porque existe defasagem nos dados apresentados pela JUCEPAR, pois o valor do capital social fora fornecido somente no momento da abertura da empresa, não sendo atualizado posteriormente. Já o montante de empreendimentos nas duas modalidades no município, demonstra a importante participação dos empreendimentos de localidade mínima, atendendo a um contexto socioespacial específico.

A cidade de Ponta Grossa com seu histórico processo de segregação socioespacial promove uma urbanização dispersa e segmentada socialmente. A venda de alimentos atende às características dos empreendimentos do circuito superior e inferior. Utilizando a variável intensidade de cor, onde a densidade calculada é baseada no número de pontos de uma localização, os mapas ordenados 01 e 02 a seguir, retratam a espacialização dos empreendimentos de venda de alimentos para consumo na residência, de alcance máximo e mínimo. Entende-se a partir destes dois mapas ${ }^{6}$ que os tipos de empreendimentos visam atender diferentes cenários socioeconômicos.

Dos 1.049 empreendimentos que compreendem os minimercados e mercearias na cidade de Ponta Grossa, o Mapa 02 espacializa 987 empreendimentos por bairros. Dos 99 empreendimentos caracterizados como supermercados e hipermercados, 87 foram espacializados por bairros no Mapa 01. Os empreendimentos que não constam no mapeamento são decorrentes da falta de informação do endereço do estabelecimento e/ou do fato de se localizarem na área rural do município, que foi desconsiderada no mapeamento.

Pelo Mapa 01 observa-se a concentração dos empreendimentos de localidade máxima nos bairros do Jardim Carvalho, Uvaranas e no Centro. A dependência de um número muito elevado de clientes para que ocorra um grande volume de vendas inviabiliza a dispersão destes empreendimentos, concentrando-se assim no centro da cidade e bairros subcentrais (Gráfico 02).

O Bairro Jardim Carvalho configura-se, junto com Oficinas e Neves, os de maior inclusão social (NASCIMENTO, 2008). O bairro de Uvaranas é o que possui o a maior população absoluta, onde os níveis de renda e inclusão social modificam-se muito conforme o local que se ocupa no bairro, que varia desde o centro periférico até o limite oriental da área urbana. Nascimento (2008) aponta para a ocorrência, no Bairro de Uvaranas, de uma grande desigualdade socioespacial, tendo 11.101 habitantes considerados incluídos socialmente paralelamente a 30.765 habitantes considerados excluídos socialmente.

6 Ambos os mapas foram confeccionados no software gratuito Quantum GIS (QGIS). 
Mapa 01 - Quantidade de hipermercados e supermercados em Ponta Grossa - PR

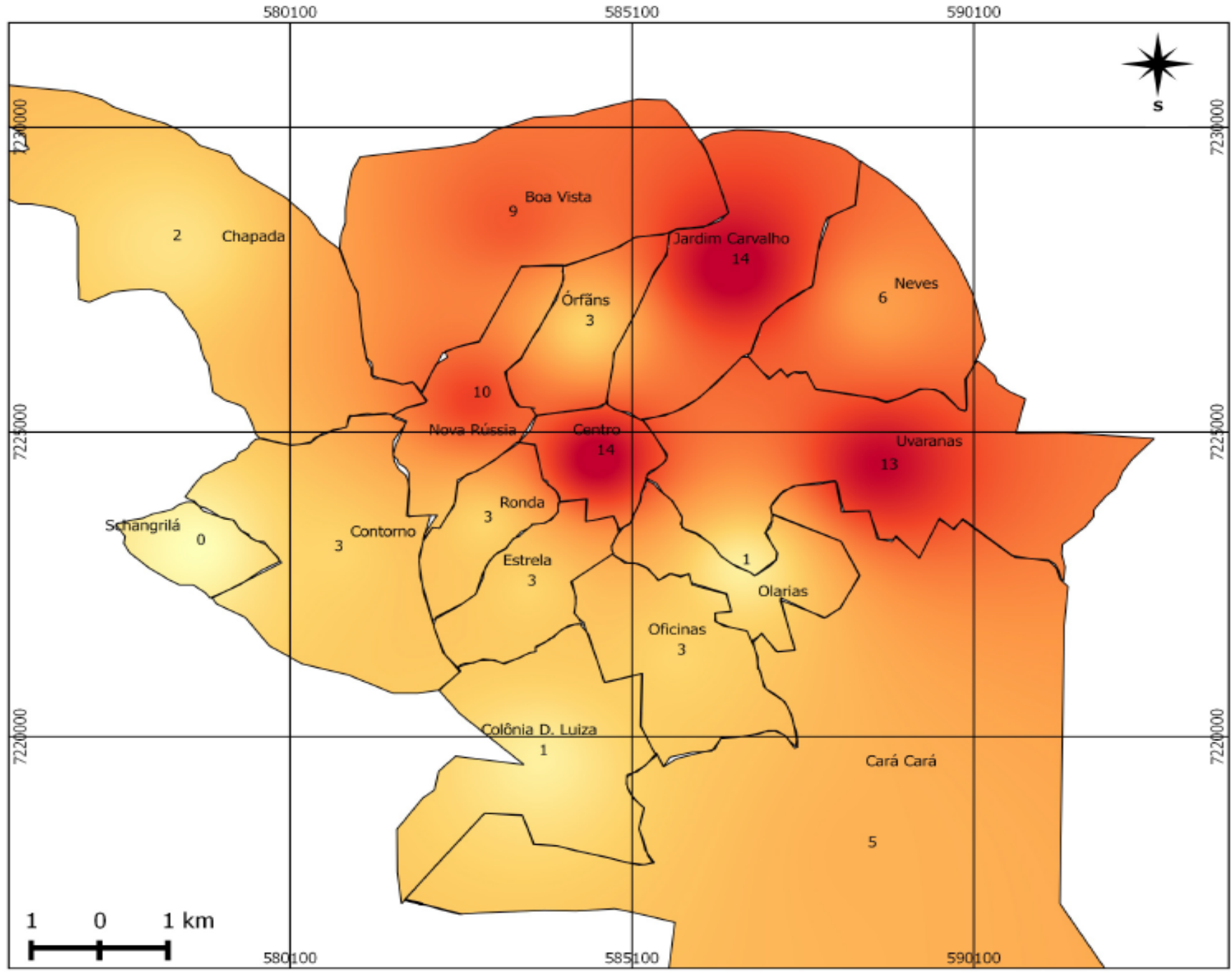

\begin{tabular}{|l|l|l|}
\hline BAIRRO & HIPERMERC & SUPERMERC \\
\hline Boa Vista & 4 & 5 \\
\hline Cará Cará & 1 & 4 \\
\hline Centro & 6 & 8 \\
\hline Chapada & 1 & 1 \\
\hline Colônia D. Luiza & 0 & 1 \\
\hline Contorno & 2 & 1 \\
\hline Estrela & 1 & 2 \\
\hline Jardim Carvalho & 6 & 8 \\
\hline Neves & 2 & 4 \\
\hline Nova Rússia & 4 & 6 \\
\hline Oficinas & 1 & 2 \\
\hline Olarias & 1 & 0 \\
\hline Ronda & 1 & 2 \\
\hline Schangrilá & 0 & 0 \\
\hline Uvaranas & 9 & 4 \\
\hline Orränn & 1 & 2 \\
\hline
\end{tabular}

Org.: o autor

Já a distribuição dos empreendimentos de localidade mínima apresenta-se de maneira mais equitativa no perímetro urbano. Por não dependerem de um número elevado de clientes para que se justifique a ocorrência do empreendimento, os mesmos não têm necessariamente de se localizar em áreas centrais, muito pelo contrário.

Analisando a tabela de número de habitantes por bairro e o Mapa 02, percebe-se que o número de minimercados e mercearias está diretamente relacionado ao maior contingente populacional. 
Gráfico 02- Número de habitantes por bairro (Ponta Grossa - PR)

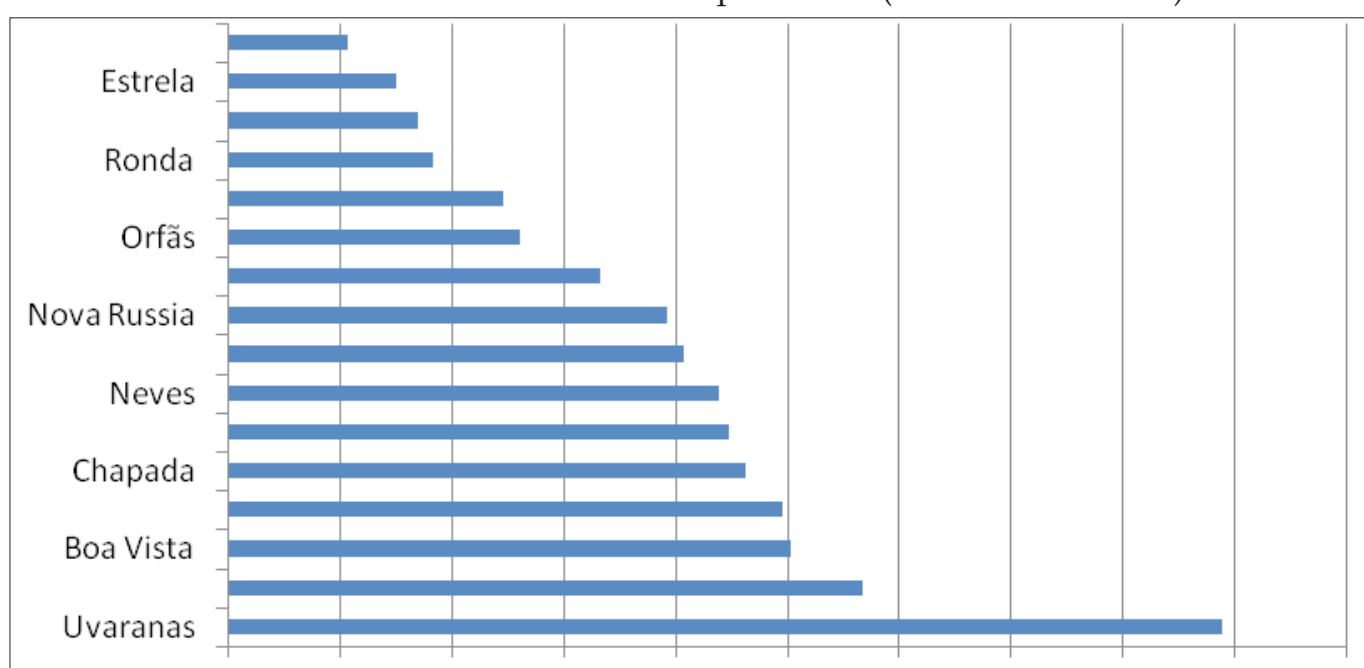

$0 \quad 5000 \quad 1000015000 \quad 20000 \quad 25000 \quad 30000 \quad 35000 \quad 40000 \quad 45000 \quad 50000$

Fonte: IBGE, 2010

Org.: o autor.

Mapa 02- Quantidade de minimercados e mercearias na cidade de Ponta Grossa-PR

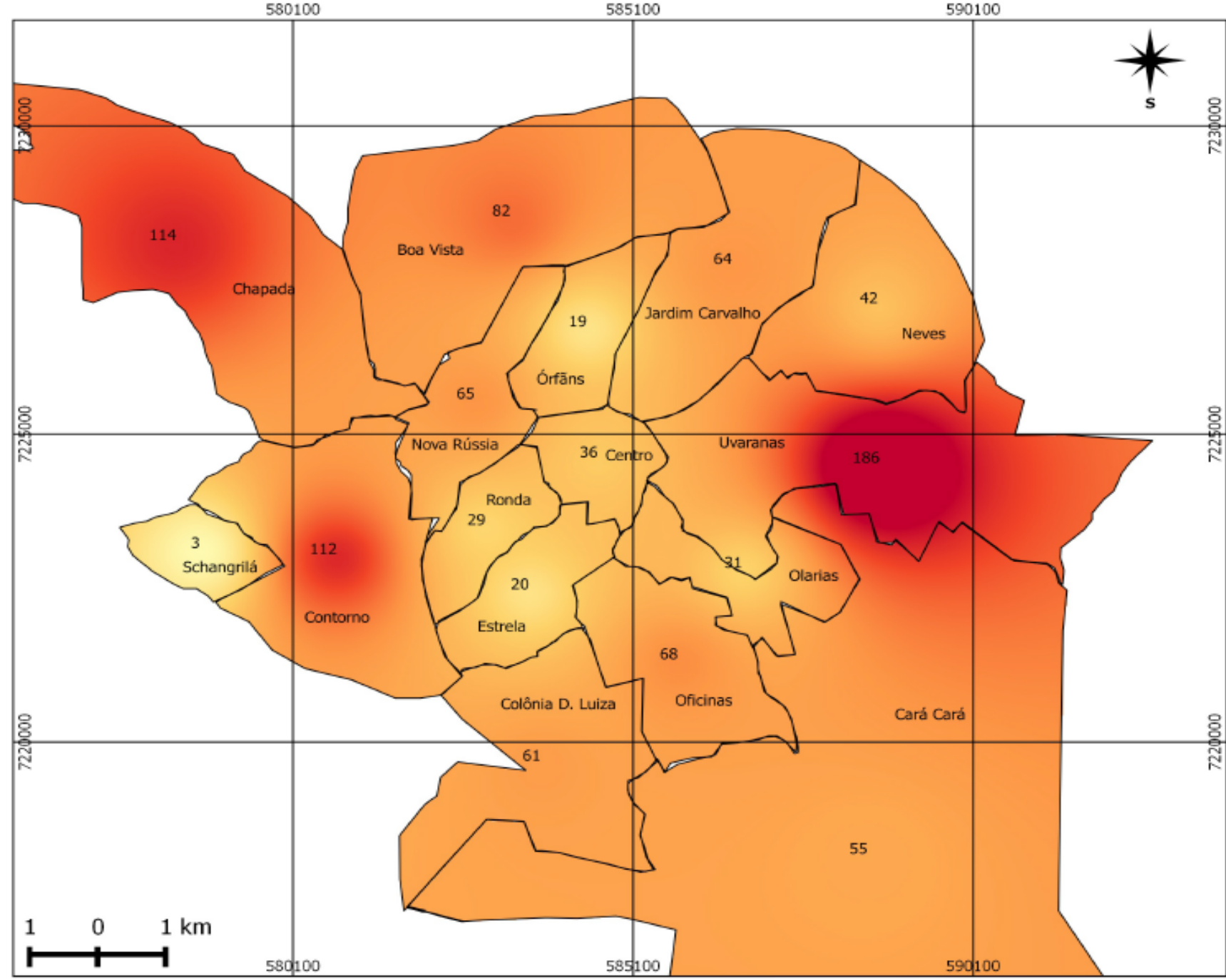

\begin{tabular}{|l|l|}
\hline BAIRRO & MINIMERC.+MERCEAR. \\
\hline Chapada & 114 \\
\hline Boa Vista & 82 \\
\hline Schangrilá & 3 \\
\hline Contorno & 112 \\
\hline Ronda & 29 \\
\hline Nova Rússia & 65 \\
\hline Centro & 36 \\
\hline Estrela & 20 \\
\hline Colôniaa D. Luiza & 61 \\
\hline Olarias & 31 \\
\hline Oficinas & 68 \\
\hline Órfäns & 19 \\
\hline Jardúm Carvalho & 64 \\
\hline Neves & 42 \\
\hline Uveranas & 186 \\
\hline Cará Cará & 55 \\
\hline &
\end{tabular}

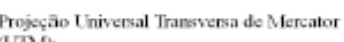
Datemu Honizantal SIRGAS 2000 Fonte de dadasestritPaR(Junta

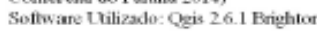

PANÁ, EGERSON. S. 2015

SANTOS. R.G.2015 
Assim como os empreendimentos 'optam'7 por sua localização como um reflexo da condição socioespacial, eles também condicionam a mesma. Se as formas de comércio de alimentos variam espacialmente conforme as classes de renda, variam também sua qualidade. Enquadra-se neste contexto para as populações de baixa renda os comércios de vendas de produtos frequentemente de menor qualidade e maior custo relativo. Estes estabelecimentos são então, reflexo e condicionante de um cenário de insegurança alimentar e social.

Considerando-se o macroambiente alimentar e a escala dos bairros, onde se averigua a densidade da disponibilidade de comercialização de alimentos próxima às residências (DURAN, 2013), percebe-se que os empreendimentos diferenciam-se na relação centro-periferia, e que para as áreas distantes do centro o macroambiente alimentar sintetiza-se principalmente pela pulverização de empreendimentos de localidade mínima. Estes empreendimentos caracterizam-se frequentemente pelo seu grau tecnológico, de organização e de capital como do circuito inferior, e atendem preferencialmente as pessoas também enquadradas neste circuito da economia urbana (SANTOS, 1979).

Para a ampliação das espacialidades possíveis para obtenção de alimentos entre outros recursos necessita-se de potencial em mobilidade, que por sua vez depende, sobretudo, de dinheiro. Deste modo, para a população com menos recursos monetários o efeito da vizinhança e a aproximação com o circuito inferior torna-se mais efetivo.

\section{A DIFERENÇA ENTRE OS VALORES DA CESTA BÁSICA}

Para se conceber uma cesta básica de alimentos preliminarmente define-se a composição média das famílias e depois a composição da cesta de alimentos a ser consumida por esta (PANIGASSI, 2005). O valor da cesta básica para Ponta Grossa vem sendo calculado e divulgado desde meados de 1996 pelo Centro de Estudos e Pesquisas Rouger Miguel Vargas (CEPRMV) vinculado à Universidade Estadual de Ponta Grossa (UEPG). Este valor é aferido em seis mercados de grande porte do município e serve famílias constituídas em média de três pessoas e renda de um a cinco salários mínimos. Para o mês de maio de 2014 a cesta básica pontagrossense composta por 34 itens custava $\mathrm{R} \$ 477,14$.

O comprometimento da cesta básica na renda do pontagrossense que ganha apenas um salário mínimo é de $65,9 \%$ da renda, realidade vivida por 21,6\% das famílias entrevistadas na Ouro Verde. Analisando o valor da cesta básica com base na renda familiar dos entrevistados, conclui-se que em média os mesmos comprometam $(35,43 \%)$ de sua renda com a cesta básica de alimentos. O comprometimento da renda com a cesta básica diminui conforme aumenta a renda, para aqueles que ganham até dois salários mínimos o comprometimento da renda é de quase um terço conforme se observa na Tabela 01.

7 Para a maioria dos empreendimentos do circuito inferior não existe opção de escolha de localidade, muitas vezes os empreendimentos são realizados nas próprias residências. 
Tabela 01- Comprometimento causado pelo valor da cesta básica na renda familiar em porcentagem

\begin{tabular}{c|c|c|c|c}
\hline Ano base 2014 & 1 salário mínimo & $\begin{array}{c}\text { 2 salários } \\
\text { mínimos }\end{array}$ & $\begin{array}{c}\text { 3 salários } \\
\text { mínimos }\end{array}$ & $\begin{array}{c}\text { 4 salários } \\
\text { mínimos }\end{array}$ \\
\hline Renda familiar (R\$) & 724,00 & $1.448,00$ & $2.117,00$ & $2.896,00$ \\
\hline $\begin{array}{c}\text { Subtraído o valor da cesta } \\
\text { básica restam (R\$) }\end{array}$ & 248,86 & 970,86 & $1.694,86$ & $2.418,86$ \\
\hline $\begin{array}{c}\text { Comprometimento } \\
\text { percentual (\%) }\end{array}$ & 65,9 & 32,95 & 22,53 & 16,47 \\
\hline
\end{tabular}

Fonte: o autor.

Para compreensão do peso da exploração sobre os preços dos alimentos pagos por aqueles que consomem no circuito inferior, realizou-se um comparativo dos valores das cestas básicas de alimentos efetuadas nos principais mercados do município calculadas pelo CEPRMV, e o valor desta mesma cesta básica de alimentos nas três pequenas mercearias mais citadas como fonte de compras pelos entrevistados da Vila Ouro Verde, denominados respectivamente $\mathrm{A}, \mathrm{B}$ e $\mathrm{C}$.

Houve bastante referência sobre a realização das compras em um supermercado localizado na Vila Santa Marta, onde concentram-se uma gama diversificada de atividades comerciais e aparatos públicos habitualmente utilizados pelos moradores da Ouro Verde, como escolas, postos de saúde, creches, entre outros. Assim, o mercado em questão também foi tomado em análise e o denominaremos como supermercado mais próximo.

O valor da cesta básica média das três mercearias levantadas $\mathrm{A}, \mathrm{B}$ e $\mathrm{C}$, contendo os mesmos 34 produtos elencados pelo CEPRMV, foi de R\$ 518,15. O valor da cesta básica média dos seis mercados de grande porte elencados pelo CEPRMV foi de R $\$ 465,48$. A diferença de $\mathrm{R} \$ 52,67$ compreende $10,16 \%$ a mais. Em relação ao supermercado mais próximo a cesta foi calculada em $\mathrm{R} \$ 482,05$, com uma diferença para mais de 6,96\% (R\$36,10). Estes valores encontram-se expressos no gráfico a seguir.

Gráfico 02- Diferença entre os valores das cestas básicas calculadas nos mercados A, B e C, pelo supermercado mais próximo e pelo CEPRMV

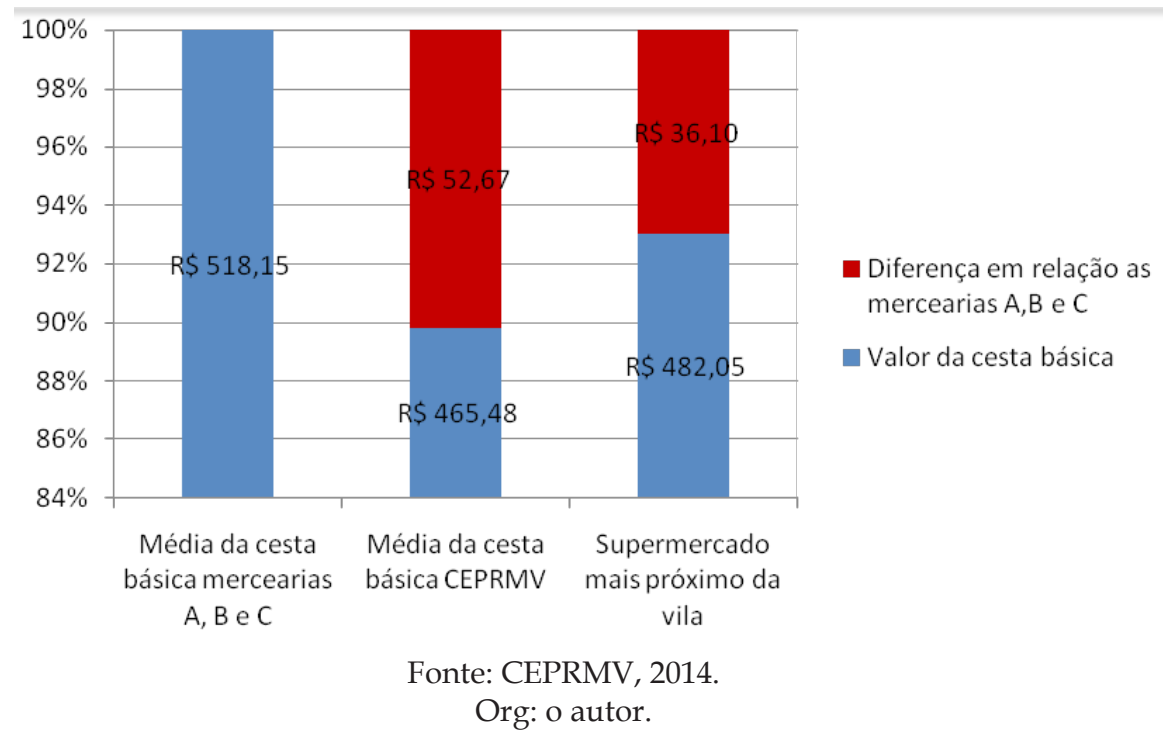


Entende-se que esta diferença é uma aproximação porque nas pequenas mercearias pesquisadas as variedades de produtos possíveis para o levantamento eram menores, já que a falta de espaço físico destes estabelecimentos não comportam tanta variedade. Devido as limitações do espaço físico os comerciantes optam por ter no estabelecimento os produtos das marcas mais baratas, pois visam também atender a uma clientela com menor poder de compra.

Estas questões nos levam a supor que a diferença nos valores da cesta básica pode ser maior do que o resultado aqui expresso, sendo mais oneroso ainda o preço praticado nas pequenas mercearias locais. Em muitos casos, no momento do levantamento dos preços dos produtos nestas pequenas mercearias, para alguns produtos havia apenas as marcas consideradas de baixa qualidade.

Apesar da qualidade inferior para alguns produtos praticados nos mercados da Vila, principalmente para bolachas e biscoitos, o valor da cesta básica ainda permaneceu maior nestes estabelecimentos. A diferença entre o valor da cesta básica mais onerosa praticada nos mercados A, B e C e o menor valor praticado entre os mercados elencados pelo CEPRMV foi de $\mathrm{R} \$ 122,61$, o que representa $22,8 \%$ a diferença entre a mercearia mais cara da Vila e o supermercado mais barato da cidade.

\section{A PROXIMIDADE COM O CONSUMO NOS COMÉRCIOS LOCAIS}

Por estar a população da Vila distante dos principais centros de consumo do município, onde os preços dos alimentos são via de regra menos onerosos, com maior gama de opções e seu acesso efetuado principalmente por automóveis individuais, torna-se caro e difícil para essa população o acesso a estas grandes redes de comércio. Das famílias entrevistadas, 39 delas $(53,4 \%)$ afirmam não possuir veículos automotores. Sobre quais eram as principais dificuldades em realizar compras nos mercados de grande porte nas áreas mais centrais, todos os entrevistados alegaram dificuldades referentes ao custo com o transporte, tempo gasto no deslocamento e precariedade do transporte coletivo, com dificuldade em carregar as sacolas de compras. Ao indagar qual desses motivos os moradores consideravam como o maior empecilho ao acesso aos grandes centros de consumo, o mais cogitado abrangendo $38,5 \%$ dos entrevistados foi o tempo despendido no deslocamento (Gráfico 03). 
Gráfico 03 - Principais dificuldades de acesso aos grandes centros de consumo.

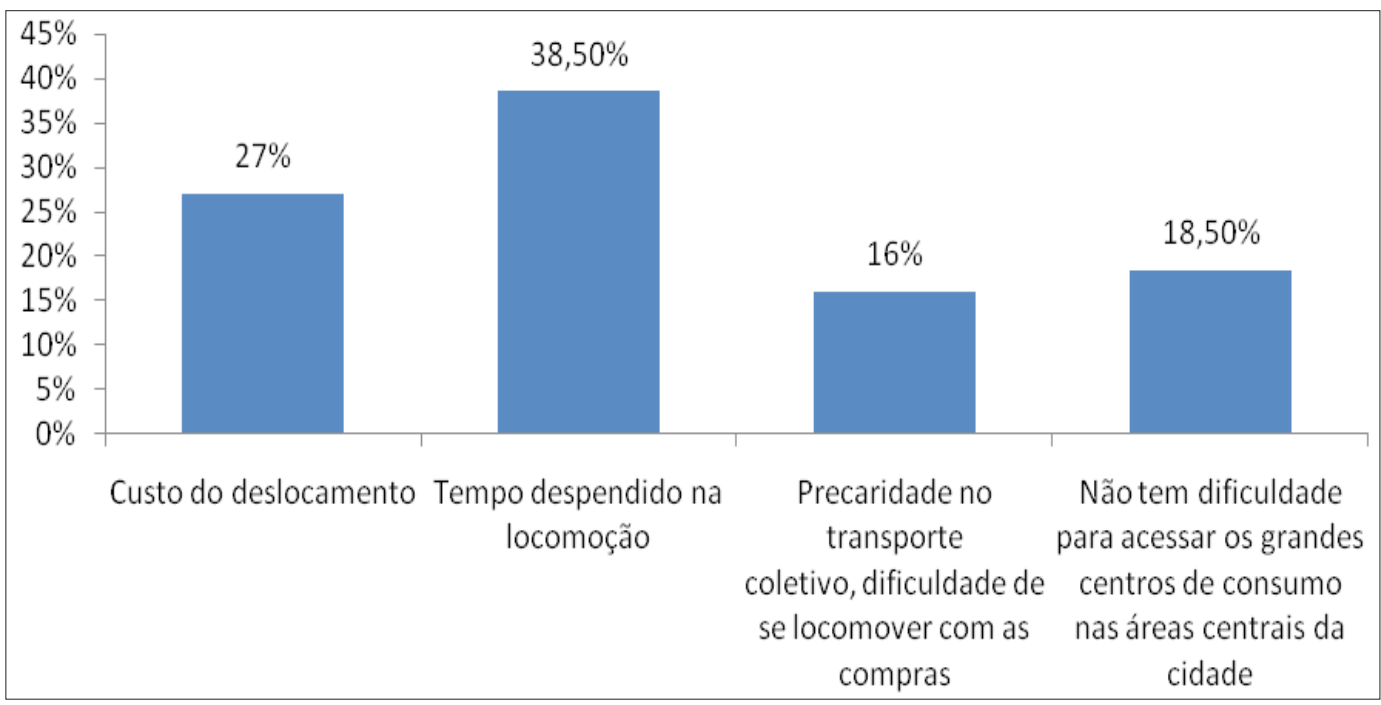

Fonte: o autor.

Sobre a aproximação dos moradores da Vila para com a compra de alimentos nos pequenos comércios locais, foram identificados dois fatores como determinantes, a modalidade de trabalho e o consumo 'fiado' (Gráfico 04). Percebe-se que a maioria das pessoas que trabalham de maneira informal consome mais nas mercearias locais e totalizam a maioria dos que possuem conta 'fiado'. Das 11 famílias que afirmam gastar entre 90 a $100 \%$ de suas compras nos mercados locais, nove delas trabalham de maneira informal e todas compram 'fiado'. Já os que possuem trabalho formal gastam menos nas mercearias locais e contabilizam uma porcentagem menor entre as pessoas que compram 'fiado'. $\mathrm{O}$ fator apresentado como preponderante para a maior porcentagem de compras e posse do crédito 'fiado' nos comércios locais foi a obtenção ou não do crédito formal, que por sua vez está intimamente vinculada ao trabalho formal.

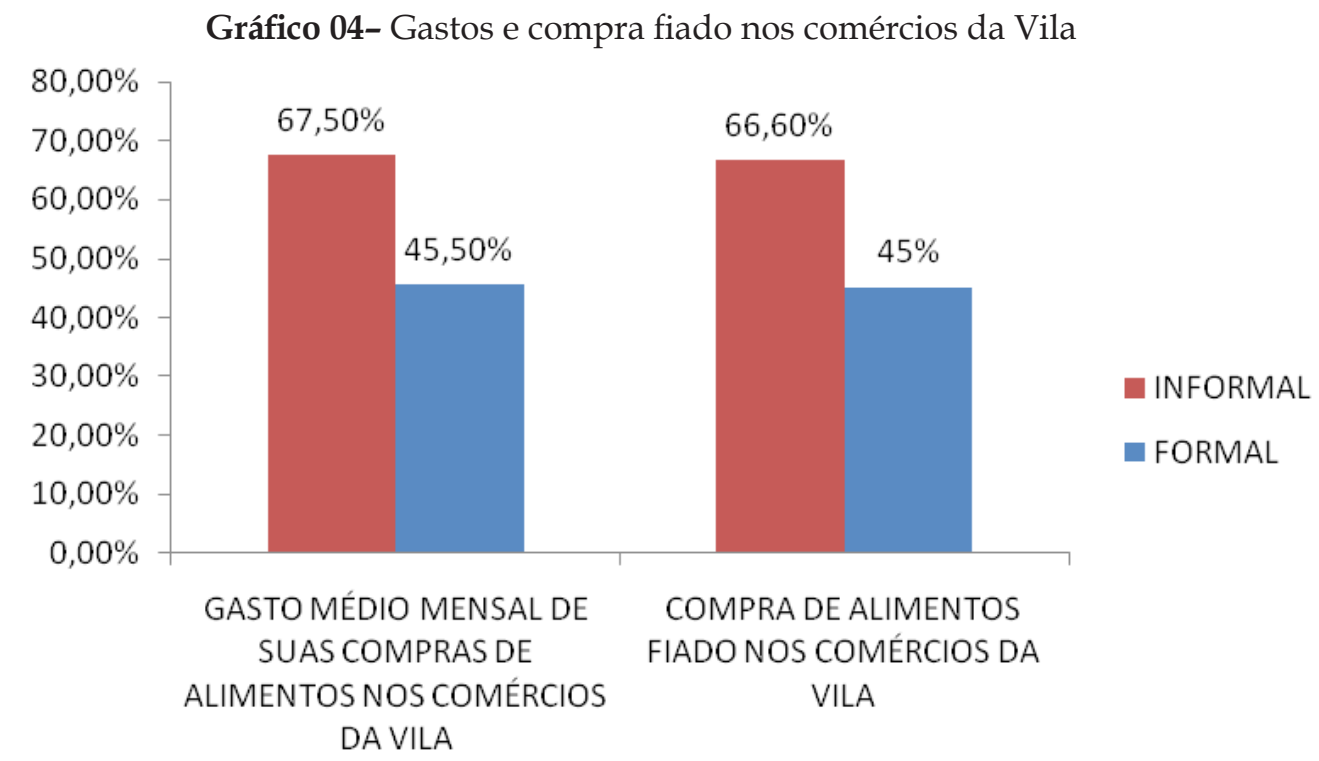

Fonte: o autor. 


\section{O MICRO AMBIENTE ALIMENTAR}

Conforme aponta Duran (2013), o microambiente alimentar compreende as variáveis dos estabelecimentos comerciais referentes à "disponibilidade, variedade, qualidade, preço, localização/distribuição dentro do estabelecimento e promoção/propaganda de alimentos" (DURAN, 2013, p.34). As observações de campo concernentes a estas variáveis nas mercearias A, B e C apontam para um microambiente alimentar não favorável à prática de uma alimentação saudável. Observa-se nos quesitos disponibilidade e variedade que as opções alimentares nos estabelecimentos pesquisados concentram-se basicamente em produtos processados, em detrimento a pouquíssimas opções de frutas e hortaliças. Para Duran (2013) estes modelos de estabelecimentos favorecem ao ambiente obesogênico, devido à promoção de alimentos de alta densidade energética. No dia 26 Maio 2014, no qual fora realizada a entrevista com os comerciantes e a análise do microambiente alimentar, a variedade de alimentos in natura nos estabelecimentos não ultrapassava a seis opções.

Quadro 02 - Opções de alimentos in natura nos estabelecimentos A, B e C

\begin{tabular}{|c|c|}
\hline Mercearia A & Tomate, batata, cebola, alface, ovo e banana \\
\hline Mercearia B & Batata, cebola, tomate, ovo, alho e banana \\
\hline Mercearia C & Batata, ovo e cebola \\
\hline
\end{tabular}

Fonte: o autor.

Nos quesitos localização/distribuição e promoção/propaganda de alimentos in natura no interior dos estabelecimentos, os mesmos encontraram-se de maneira desfavorável ao consumo. A localização escolhida para venda destes produtos eram as de menor visibilidade, parecendo muitas vezes estar 'escondidos' no interior do estabelecimento.

\section{CONSIDERAÇÕES FINAIS}

O objetivo principal deste trabalho foi contribuir à compreensão da fome urbana. $\mathrm{O}$ trabalho demonstra o Circuito Inferior, da Economia Urbana, contribui na definição das escolhas dos espaços de compra dos alimentos da população da Vila Ouro Verde. Toda esta dinâmica que se desenrola no espaço intraurbano apresenta-se prejudicial principalmente para o morador pobre da periferia urbana, que tem em seus microambientes e macroambientes alimentares condições menos favoráveis a uma alimentação saudável.

De acordo com as análises realizadas a partir dos dados adquiridos pela JUCEPAR, para as populações mais distantes do centro da cidade de Ponta Grossa destinam-se os empreendimentos comerciais menos modernos, com menores opções de alimentos. Sendo assim, o macroambiente alimentar do morador pobre da periferia constitui-se principalmente por empreendimentos característicos do circuito inferior da economia urbana.

A forma de sobrevivência ligada ao circuito inferior, para os citadinos carentes de capital e qualificação profissional, encontra na pulverização dos comércios sua lógica espacial. Esses pequenos comércios, como os pesquisados no Ouro Verde, atendem às 
necessidades dos citadinos pobres enquanto trabalhadores e consumidores. Esses comércios são adaptados à realidade local, na qual a renda é baixa e instável, e tem por característica o fracionamento das compras.

A análise dos valores das cestas básicas praticadas nas mercearias da Vila e nos principais hipermercados em áreas mais centrais elencados pelo CEPRMV, mostra que os preços pagos pelos citadinos mais pobres, consumidores da extremidade da cadeia de intermediários, que se configuram nos mercados da Vila, é consideravelmente mais onerosa. Sem dúvida, o acirramento das despesas com alimentos, somadas a tantas outras despesas de uma vida urbana podem acarretar a fome quantitativa, que em ambientes urbanos é principalmente motivada pela insuficiência de renda. Acrescentam-se ainda as poucas opções de alimentos saudáveis pertencentes nestes estabelecimentos que favorecem a prática de uma alimentação monótona, que pode acarretar no tipo mais comum de fome ocorrente no Brasil, a fome qualitativa ou específica.

Percebe-se que justamente as pessoas com menos poder aquisitivo são as que pagam um maior preço pela sua alimentação, comprometendo uma grande parte do orçamento familiar com esse gasto. Essa situação se acirra ainda mais quando o consumo de alimentos ocorre majoritariamente em empreendimentos característicos do circuito inferior.

A diferença dos valores das cestas básicas das pequenas mercearias comparada às realizadas nos grandes centros, associada às dificuldades de deslocamento da população com destaque para o tempo despendido para o mesmo, retrata um condicionamento espacial da realidade social.

As características socioespaciais da comunidade comprovaram as teorias em voga que defendem que a localização define a posição de consumo. Portanto, a maior fatia no processo de exploração capitalista, da retirada da mais valia do proletariado, encontra-se no momento do consumo, que no caso de moradores das periferias urbanas significa um duplo processo de exploração, não apenas no trabalho, mas também no seu local de moradia.

A prática do 'fiado', como a do mascate ${ }^{8}$, entre outras tantas que ocorrem nas periferias urbanas, demonstram que há uma microeconomia adaptada para um cenário de insegurança social. Comprovou-se que esta dinâmica é própria do circuito inferior da economia urbana, composta por atividades de pequena dimensão criada como forma de sobrevivência para grande parte da população.

Tanto a prática do 'fiado' como a constatação de que os valores da cesta básica são superiores nos comércios da Vila, não podem ser relacionadas a uma mera exploração dos comerciantes. Mas sim uma lógica de empreendimento adaptada a uma realidade específica. Infelizmente, não tivemos acesso à renda destes comerciantes, mas acredita-se que a lógica destes empreendimentos são aquelas identificadas por Santos (1979) para o circuito inferior, onde uma maior margem de lucro unitário dos produtos é relacionada a uma margem de lucro global pequena destes comerciantes.

8 Os moradores chamam de mascates os vendedores ambulantes que passam vendendo cesta básica de porta em porta, estes vendedores chegam a parcelar a cesta em quatro vezes, adaptando desta forma seu comércio à instável renda dos catadores de reciclagem por exemplo. 
Portanto, vive-se 'preso' a um contexto social relacionado ao consumo do circuito inferior, que explora os citadinos pobres também pelo custo de vida. Estar 'preso' é estar mais vulnerável aos efeitos de vizinhança, e se esta vizinhança tratar-se de um espaço socioespacialmente segregado, estar 'preso' também é aproximar-se da pobreza e da fome. Tanto trabalhar quanto consumir no circuito inferior apresenta-se como agravante da pobreza, destarte, da própria fome.

A atual lógica capitalista concentracionista que visa à retenção dos investimentos públicos com fins ao desenvolvimento da economia moderna do circuito superior, deixa o circuito inferior a sua própria sorte. Dessa maneira, todos os participantes do circuito inferior, sejam consumidores ou trabalhadores, ou mesmo pequenos negociantes, acabam sendo prejudicados, inclusive quando da aquisição dos alimentos.

Para a superação desse cenário, fazem-se necessárias políticas que corroborem para o desenvolvimento dos comércios varejistas enquadrados como pertencentes ao circuito inferior. Os comerciantes reteriam mais capitais, poderiam ampliar o empreendimento, oferecendo desta forma a população local uma maior variedade de alimentos a melhores preços. Essas ações somadas a majoração do poder de compra da população mais carente, e incentivos à educação alimentar poderiam sanar as mazelas constatadas nesta pesquisa.

A fome se constitui num grande problema mundial, porém solucionável (FAO, 2012). Para que se possa equacionar e resolver o problema necessita-se, antes de qualquer coisa, fomentar a discussão sobre seus diferentes condicionantes em diferentes localidades e escalas.

\section{REFERÊNCIAS}

CASEMIRO, Juliana P.; VALLA, Victor V.; GUIMARÃES, Maria B.L. Direito a alimentação adequada: um olhar urbano. Ciência e Saúde Coletiva, v. 15, p.2085-2093, 2010.

CASTRO, Josué Apolônio. Geografia da fome. Rio de Janeiro: Gryphus, 1946.

DURAN, Ana Fonseca Leitão. Ambiente alimentar urbano em São Paulo, Brasil: avaliação, desigualdades e associação com consumo alimentar. São Paulo, 2013. 276 p. Tese (Doutorado em Nutrição em Saúde Pública) - Universidade de São Paulo.

FAO. Food and Agriculture Organization of the United Nations. O que você precisa saber sobre a fome. Disponível em: <https:/ / www.fao.org.br/oqvpssf2012.asp> Acesso em: 15 Set. 2012.

IBGE. Instituto Brasileiro de Geografia e Estatística. Censo Demográfico de 2010.

JUCEPAR. Junta comercial do estado do Paraná. Disponível em: <http://www.juntacomercial.pr.gov.br/ modules/conteudo/conteudo.php?conteudo=80> Acesso em: 15 Set. 2012.

NASCIMENTO, Ederson. Espaço e desigualdades: mapeamento e análise dinâmica de exclusão/inclusão social na cidade de Ponta Grossa (PR). Ponta Grossa, 2008. 172 p. Dissertação (Mestrado em Gestão do Território) - Universidade Estadual de Ponta Grossa.

PANIGASSI, Giseli. Inquérito populacional sobre a percepção da segurança alimentar intrafamiliar no município de Campinas, SP. Campinas, 2005. 181 p. Tese (Doutorado em Ciências Médicas) - Universidade Estadual de Campinas.

PEET, Richard. Desigualdade e pobreza uma teoria geográfica marxista. In: CHRISTOFOLETTI, Antonio (Org.). Perspectivas da Geografia. Rio Claro: Difel, 1982. p. 255-268. 
PUTNAM, Robert. Comunidade e Democracia: a experiência da Itália moderna. Rio de Janeiro: FGV, 2006.

SANTOS, Milton. O Espaço Dividido. Os dois circuitos da economia urbana dos países subdesenvolvidos. Rio de Janeiro: Francisco Alves, 1979.

SPOSITO, Eliseu Savério. A Teoria dos dois circuitos da economia urbana nos países subdesenvolvidos: seu esquecimento ou sua superação? In: SOUZA, Alvaro José et al. (Eds.). Milton Santos: cidadania e globalização. Bauru: AGB/ Saraiva, 2000. p.43-51. 